\title{
High dimensional and high resolution pulse sequences for backbone resonance assignment of intrinsically disordered proteins
}

\author{
Anna Zawadzka-Kazimierczuk • Wiktor Koźmiński • \\ Hana Šanderová • Libor Krásný
}

Received: 22 November 2011/ Accepted: 30 January 2012/Published online: 17 February 2012

(C) The Author(s) 2012. This article is published with open access at Springerlink.com

\begin{abstract}
Four novel 5D (HACA(N)CONH, HNCO$\mathrm{CACB},(\mathrm{HACA}) \mathrm{CON}(\mathrm{CA}) \mathrm{CONH},(\mathrm{H}) \mathrm{NCO}(\mathrm{NCA}) \mathrm{CONH})$, and one $6 \mathrm{D}((\mathrm{H}) \mathrm{NCO}(\mathrm{N}) \mathrm{CACONH}) \mathrm{NMR}$ pulse sequences are proposed. The new experiments employ non-uniform sampling that enables achieving high resolution in indirectly detected dimensions. The experiments facilitate resonance assignment of intrinsically disordered proteins. The novel pulse sequences were successfully tested using $\delta$ subunit (20 kDa) of Bacillus subtilis RNA polymerase that has an 81-amino acid disordered part containing various repetitive sequences.
\end{abstract}

Keywords Intrinsically disordered proteins .

Non-uniform sampling · Backbone assignment .

5D NMR · 6D NMR

\section{Introduction}

Intrinsically disordered proteins (IDPs) are a group of macromolecules with peculiar structure, dynamics and interactions (Dyson and Wright 2001; Tompa et al. 2006) that allow them to play a number of important biological functions (Ward et al. 2004; Dyson and Wright 2005; Tompa 2010). Solution state NMR spectroscopic

A. Zawadzka-Kazimierczuk · W. Koźmiński $(\square)$

Faculty of Chemistry, University of Warsaw,

Pasteura 1, 02-093 Warsaw, Poland

e-mail: kozmin@chem.uw.edu.pl

H. Šanderová · L. Krásný

Laboratory of Molecular Genetics of Bacteria, Department of Bacteriology, Institute of Microbiology, Academy of Sciences of the Czech Republic, Vídeňská 1083, 14220 Prague, Czech Republic techniques appear ideally suited for the studies of these proteins as IDPs' fast conformational dynamics results in relatively slow transverse relaxation rates. The problem is that the rapid interconversion rate for the various conformations causes averaging of chemical shifts and very poor peak separation, making resonance assignment difficult, even for relatively small disordered protein fragments. However, there is a promise for solving this obstacle in multidimensional NMR methods utilizing non-uniform sampling of indirectly detected dimensions (Felli and Brutscher 2009; Coggins et al. 2010; Kazimierczuk et al. 2010a), as this sampling facilitates acquisition of highresolution and high-dimensional spectra.

The established approach for backbone resonance assignment of globular proteins consists of a suite of triple-resonance experiments where sequential connectivities are found using carbonyl ${ }^{13} \mathrm{C}$, aliphatic ${ }^{13} \mathrm{C}$ and/or aliphatic ${ }^{1} \mathrm{H}$ chemical shifts (Sattleretal.1999).However,thisapproachoftenfailsinthecase ofIDPsbecauseof poordispersionof side-chainchemicalshifts (whichdependmostlyontheresidueidentity).InFig. 1,weshow HA-CA,HB-CBandN-COchemicalshiftcorrelationsforthe 81 a.a. unstructured part of the $\delta$ subunit of $B$. subtilis RNA polymerase (Motáčková et al. 2010; Nováček et al. 2011). These graphs clearly show the best dispersion of amide nitrogen and carbonyl carbon chemical shifts. The utility of these nuclei for sequential assignment is additionally supported by their relatively slow (ascompared to that of aliphatic protonsoraliphatic carbon atoms) transverse relaxation and lack of non-refocused homonuclear couplings, the presence of which may limit resolutionevenstrongerthandoestherelaxationlimit,e.g.inthecase ofaliphaticcarbonatoms.

To date, several strategies have been proposed for effective backbone resonance assignment of IDPs. These strategies include ${ }^{13} \mathrm{C}$ detection (Bermel et al. 2006, 2009), automated projection spectroscopy (APSY; Narayanan 

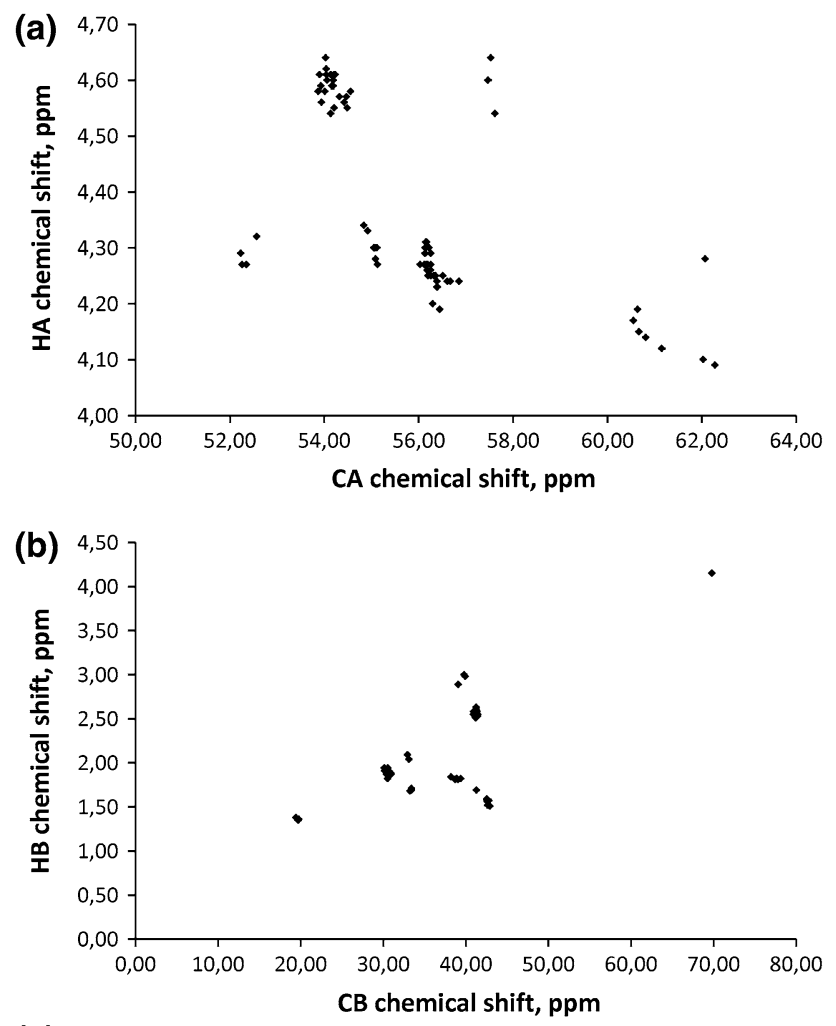

(c)

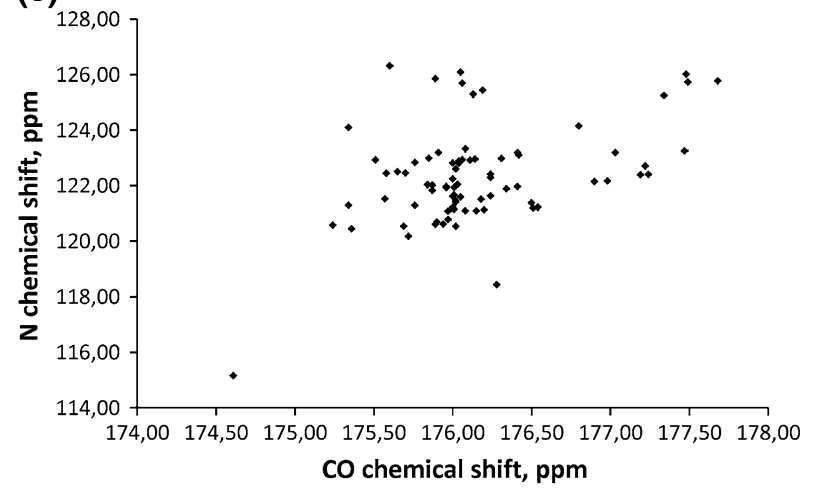

Fig. 1 Correlation of HA-CA (a), HB-CB (b), and N-CO (c) chemical shifts for the 81 a.a. unstructured part of the $\delta$ subunit of B. subtilis RNA polymerase. The ${ }^{1} \mathrm{H}$ and ${ }^{13} \mathrm{C}$ chemical shifts depend mostly on particular amino acid residue, whereas ${ }^{13} \mathrm{CO}$ and ${ }^{15} \mathrm{~N}$ frequencies are much better resolved and enable identification of backbone connectivity. (BMRB entry 16912)

et al. 2010), HA detection (Mäntylahti et al. 2011), and the sparsely sampled 4D (Wen et al. 2011) and 5D experiments (Motáčková et al. 2010; Nováček et al. 2011). Below, we propose a set of new pulse sequences that feature high resolution and high dimensionality resulting from the use of sparse random sampling in the indirectly detected dimensions. The novel experiments, which require (because of multiple coherence transfer steps involved) a slow transverse relaxation, were designed for IDPs and are superior in terms of peak resolution and the easiness of resonance assignment of the proteins. The pulse sequences were tested using the $20 \mathrm{kDa} \delta$ subunit of $B$. subtilis RNA polymerase. Having an 81 a.a. unstructured part with various repetitive sequences, this macromolecule is an excellent example of an IDP whose resonance assignment is extremely difficult using conventional methods.

\section{Methods}

The uniformly ${ }^{13} \mathrm{C},{ }^{15} \mathrm{~N}$-labeled sample of $B$. subtilis RNA polymerase $\delta$ subunit was prepared as described previously (Motáčková et al. 2010). All spectra were acquired in a $0.7 \mathrm{mM}$ protein solution sample on a Varian NMR System 700 spectrometer equipped with a Performa XYZ PFG unit, using the standard $5 \mathrm{~mm}{ }^{1} \mathrm{H}_{-}{ }^{13} \mathrm{C}^{-15} \mathrm{~N}$ triple-resonance probehead. High-power ${ }^{1} \mathrm{H},{ }^{13} \mathrm{C}$ and ${ }^{15} \mathrm{~N} \pi / 2$ pulses of 5.9, 13.5 and $31.0 \mu \mathrm{s}$, respectively, were used. Selective CA and $\mathrm{CO}$ pulses were realized as phase-modulated (for offresonance excitation or inversion) sinc shapes, with $\mathrm{B}_{1}$ field strength adjusted to have a minimal effect on $\mathrm{CO}$ and CA, respectively. In all cases, four scans per each data set were acquired with acquisition time of $85 \mathrm{~ms}$ and relaxation delay of $1.2 \mathrm{~s}$. For processing of directly detected dimension, cosine square weighting function was used prior to Fourier transform with zero-filling to $2,048 \mathrm{com}$ plex points. The experiments were performed using random off-grid Poisson disk sampling with sampling density set according to a Gaussian distribution $(\sigma=0.5)$ with regard to maximum evolution time (Kazimierczuk et al. 2008). No apodization was applied in indirect dimensions. The number of complex points $\mathrm{M}_{\mathrm{i}}$ in the frequency domain of $i$ th indirectly detected dimension was set as $\mathrm{M}_{\mathrm{i}} \geq 3 \times \mathrm{sw}_{\mathrm{i}} \times \mathrm{t}_{\mathrm{i}}^{\max }$. The sparse multidimensional Fourier transform (SMFT) procedure (Kazimierczuk et al. 2009), with 'fixed' frequencies derived from $3 \mathrm{D}$ HNCO and 4D HNCOCA peak list, was used to obtain $F_{1} / F_{2}$ cross-sections in 5D and $6 \mathrm{D}$ experiments, respectively. The remaining relevant experimental parameters are shown in Table 1.

The pulse sequences were written using own-developed programming library. The resulting spectra were analyzed using the SPARKY software (Goddard and Kneller 2002). The pulse sequence code for Agilent spectrometers as well as the SMFT software used for data processing are available from the authors upon request.

\section{Results and discussion}

The first two pulse sequences (5D HACA(N)CONH and 5D (HACA)CON(CA)CONH) are depicted schematically in Figs. 2a and 3a, respectively, and the corresponding coherence transfer pathways are given in Figs. $2 \mathrm{~b}$ and $3 \mathrm{~b}$. 
Table 1 Maximum evolution times $\left(t^{\mathrm{max}}, \mathrm{ms}\right)$ and spectral width (sw, kHz) used for acquisition of spectra for $B$. subtilis RNA polymerase $\delta$ subunit

\begin{tabular}{|c|c|c|c|c|c|}
\hline & $\begin{array}{l}\text { 5D } \\
\mathrm{HACA}(\mathrm{N}) \mathrm{CONH}\end{array}$ & $\begin{array}{l}\text { 5D } \\
\text { HNCOCACB }\end{array}$ & $\begin{array}{l}\text { 5D } \\
(\mathrm{H}) \mathrm{NCO}(\mathrm{NCA}) \mathrm{CONH}\end{array}$ & $\begin{array}{l}6 \mathrm{D} \\
(\mathrm{H}) \mathrm{NCO}(\mathrm{N}) \mathrm{CACONH}\end{array}$ & $\begin{array}{l}5 \mathrm{D} \\
(\mathrm{HACA}) \mathrm{CON}(\mathrm{CA}) \mathrm{CONH}\end{array}$ \\
\hline Number of points & 1,000 & 1,300 & 1,570 & 1,000 & 770 \\
\hline Experiment duration (h) & 23.0 & 29.5 & 36.0 & 45.5 & 17.5 \\
\hline $\mathrm{sw}_{1}$ & 4 & 14 & 2.8 & 2.8 & 3.8 \\
\hline $\mathrm{sw}_{2}$ & 6.2 & 14 & 3 & 3 & 3 \\
\hline $\mathrm{sw}_{3}$ & 3 & 3 & 3 & 6.2 & 3 \\
\hline $\mathrm{sw}_{4}$ & 2.8 & 2.8 & 2.8 & 3 & 3.8 \\
\hline $\mathrm{sw}_{5}$ & n.a. & n.a. & n.a. & 2.8 & n.a. \\
\hline$t_{1}^{\max }$ & 20 & 10 & 50 & 50 & 50 \\
\hline$t_{2}^{\max }$ & 10 & 10 & 45 & 45 & 45 \\
\hline$t_{3}^{\max }$ & 45 & 45 & 45 & 28.6 & 45 \\
\hline$t_{4}^{\max }$ & 75 & 75 & 75 & 45 & 75 \\
\hline$t_{5}^{\max }$ & n.a. & n.a. & n.a. & 75 & n.a. \\
\hline $\begin{array}{l}\text { Sampling density versus } \\
\text { conventional }\end{array}$ & $7.11 \times 10^{-6}$ & $2.34 \times 10^{-6}$ & $2.93 \times 10^{-6}$ & $1.05 \times 10^{-8}$ & $7.80 \times 10^{-7}$ \\
\hline
\end{tabular}
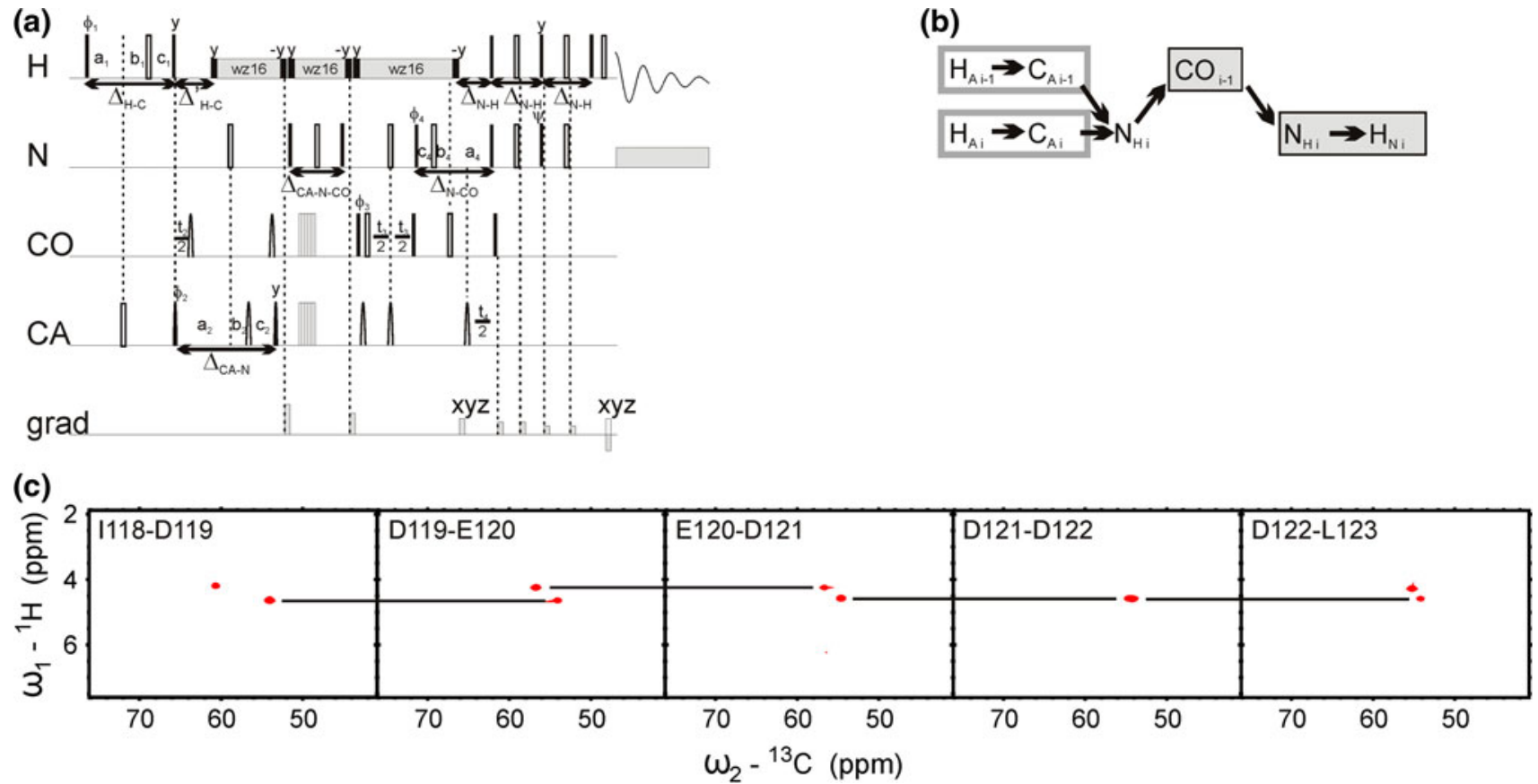

Fig. 2 DD HACA(N)CONH technique. (a) Pulse sequence, ${ }^{1} \mathrm{H},{ }^{13} \mathrm{CA}$, and ${ }^{15} \mathrm{~N}$ evolution is in semi-constant-time mode: $a_{i}=\left(t_{i}+\Delta\right) / 2$, $b_{\mathrm{i}}=t_{\mathrm{i}}\left(1-\Delta / t_{\mathrm{i}}^{\max }\right) / 2, c_{\mathrm{i}}=\Delta\left(1-t_{\mathrm{i}} / t_{\mathrm{i}}^{\max }\right) / 2$ (where $\Delta$ stands for coherence transfer delays listed below, $t_{\mathrm{i}}$ is the evolution time in $i$ th dimension, and $t_{\mathrm{i}}^{\max }$ is maximal length of the evolution time delay). Delays were set as follows: $\Delta_{\mathrm{H}-\mathrm{C}}^{\prime}=2.6 \mathrm{~ms}, \Delta_{\mathrm{CA}-\mathrm{N}}=28.0 \mathrm{~ms}, \Delta_{\mathrm{CA}-}$ $\mathrm{N}-\mathrm{CO}=28.0 \mathrm{~ms}, \Delta_{\mathrm{N}-\mathrm{CO}}=28.0 \mathrm{~ms}$, and $\Delta_{\mathrm{N}-\mathrm{H}}=5.4 \mathrm{~ms}$. The fourstep phase cycle was used: $\phi_{1}=\mathrm{x},-\mathrm{x}, \phi_{2}=2 \mathrm{x}, 2(-\mathrm{x})$ and $\operatorname{Rec}=\phi_{1}+\phi_{2}$. Simultaneous inversion of $\mathrm{CA}$ and $\mathrm{CO}$ spins was achieved using 6-element composite pulse (Shaka 1985). The coherence selection gradients (marked xyz) were applied at the magic

Both experiments employ equilibrium magnetization of HA protons. This allows identifying certain chemical shifts of the proline residues whose successors' amide protons are angle. The phase $\psi$ was inverted simultaneously with the last gradient pulse. (b) Coherence transfer in the peptide chain. $\mathrm{H}^{\mathrm{N}}, \mathrm{N}$, and $\mathrm{CO}$ frequencies (filled rectangles) are 'fixed' for Fourier transform. Frames for HA and CA indicate the dimensions of 2D cross-sections obtained by SMFT procedure. (c) 2D spectral planes for the $\delta$ subunit of B. subtilis RNA polymerase, which were obtained by SMFT procedure performed on the 5D randomly sampled signal (Poisson disk sampling) with 'fixed' frequencies obtained from 3D HNCO peak list. Each cross-section contains two cross-peaks: for' fixed' $\mathrm{H}_{\mathrm{i}}^{\mathrm{N}}$, $\mathrm{N}_{\mathrm{i}}$ and $\mathrm{CO}_{\mathrm{i}-1}$, the peaks correspond to $\mathrm{HA}_{\mathrm{i}}-\mathrm{CA}_{\mathrm{i}}$ and $\mathrm{HA}_{\mathrm{i}-1}-\mathrm{CA}_{\mathrm{i}-1}$ correlations

detected. In both experiments, the effective separation of $F_{1} / F_{2}$ cross-sections is obtained due to the good peak separation in $\mathrm{CO}-\mathrm{N}$ subspectra. In the $\mathrm{HACA}(\mathrm{N}) \mathrm{CONH}$ 

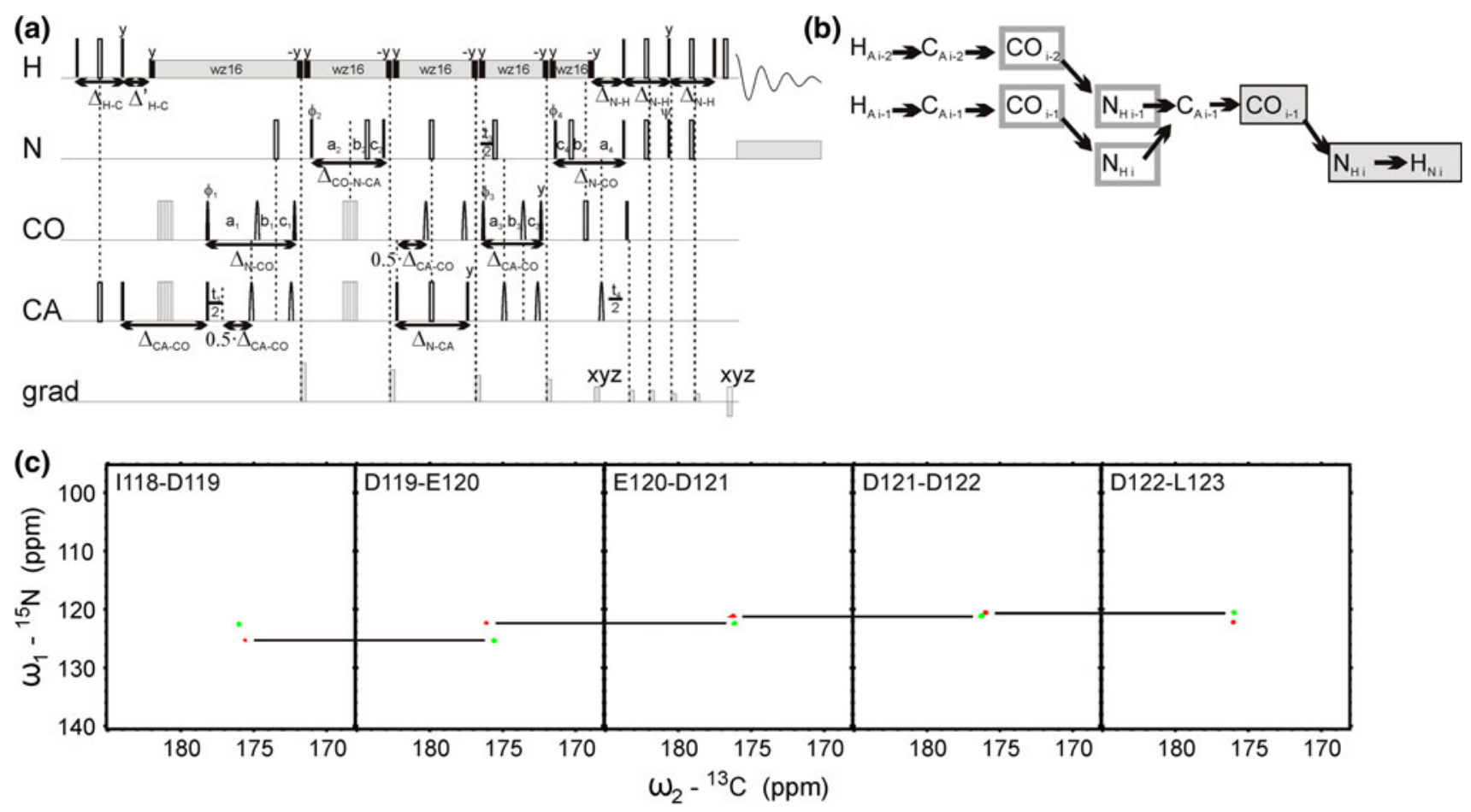

Fig. 3 5D (HACA)CON(CA)CONH technique. (a) Pulse sequence, ${ }^{15} \mathrm{~N}$ (in $t_{2}$ and $t_{4}$ ) and ${ }^{13} \mathrm{CO}$ (in $t_{1}$ and $t_{3}$ ) evolution is in semi-constanttime mode: $\mathrm{a}_{\mathrm{i}}=\left(t_{\mathrm{i}}+\Delta\right) / 2, b_{\mathrm{i}}=t_{\mathrm{i}}\left(1-\Delta / t_{\mathrm{i}}^{\max }\right) / 2, c_{\mathrm{i}}=\Delta\left(1-t_{\mathrm{i}} / t_{\mathrm{i}}^{\max }\right) / 2$ (where $\Delta$ stands for coherence transfer delays listed below, $t_{\mathrm{i}}$ is the evolution time in $i$ th dimension, and $t_{\mathrm{i}}^{\max }$ is maximal length of the evolution time delay). Delays were set as follows: $\Delta_{\mathrm{H}-\mathrm{C}}=3.7 \mathrm{~ms}$, $\Delta_{\mathrm{H}-\mathrm{C}}^{\prime}=2.6 \mathrm{~ms}, \Delta_{\mathrm{CA}-\mathrm{CO}}=6.8 \mathrm{~ms}, \Delta_{\mathrm{CA}-\mathrm{N}}=28.0 \mathrm{~ms}, \Delta_{\mathrm{CA}-\mathrm{N}-\mathrm{CO}}=$ $28.0 \mathrm{~ms}, \Delta_{\mathrm{N}-\mathrm{CO}}=28.0 \mathrm{~ms}, \Delta_{\mathrm{N}-\mathrm{H}}=5.4 \mathrm{~ms}$. The four-step phase cycle was used: $\phi_{1}=\mathrm{x},-\mathrm{x}, \phi_{2}=2 \mathrm{x}, 2(-\mathrm{x})$ and $\mathrm{Rec}=\phi_{1}+\phi_{2}$. Simultaneous inversion of $\mathrm{CA}$ and $\mathrm{CO}$ spins was achieved using 6-element composite pulse (Shaka 1985). The coherence selection

experiment, the sequential connectivities may be obtained from ${ }^{1} \mathrm{HA}$ and ${ }^{13} \mathrm{CA}$ chemical shifts, which approach usually fails in the case of IDPs due to poor peak separation. On the other hand, the (HACA)CON(CA)CONH spectra allow, at the expense of additional coherence transfer steps, finding of connectivities with the use ${ }^{13} \mathrm{CO}$ and ${ }^{15} \mathrm{~N}$ frequencies that are more uniformly distributed over the entire spectral band and therefore are more suitable for the studies of IDPs. This experiment requires extension of the spectral width in the first two dimensions to accommodate correlations of proline residues. In Figs. $2 \mathrm{c}$ and $3 \mathrm{c}$ we show an example of $2 \mathrm{D}$ cross-sections for the I118-L123 fragment of the disordered part of $\delta$ subunit of $B$. subtilis RNA polymerase.

The out-and-back 5D HNCOCACB experiment shown in Fig. 4 correlates ${ }^{1} \mathrm{H}_{\mathrm{i}}^{\mathrm{N}},{ }^{15} \mathrm{~N}_{\mathrm{i}},{ }^{13} \mathrm{CO}_{\mathrm{i}-1}$ with ${ }^{13} \mathrm{CA}_{\mathrm{i}-1}$ and ${ }^{13} \mathrm{CB}_{\mathrm{i}-1}$ chemical shifts. Contrary to the established CBCANH, CBCA(CO)NH and HNCACB experiments (Grzesiek and Bax 1992a, 1992b, 1993; Wittekind and Müller 1993), the CA and CB evolutions are performed in gradients (marked by xyz) were applied at the magic angle. The phase $\psi$ was inverted simultaneously with the last gradient pulse. (b) Coherence transfer in the peptide chain. $\mathrm{H}^{\mathrm{N}}, \mathrm{N}$, and $\mathrm{CO}$ frequencies (filled rectangles) are 'fixed' for Fourier transform. Frames for $\mathrm{N}$ and $\mathrm{CO}$ indicate the dimensions of 2D cross-sections obtained by SMFT procedure. (c) 2D spectral planes for the $\delta$ subunit of $B$. subtilis RNA polymerase, which were obtained by SMFT procedure performed on the 5D randomly sampled signal (Poisson disk sampling) with 'fixed' frequencies obtained from 3D HNCO peak list. Each cross-section contains two cross-peaks: for 'fixed' $\mathrm{H}_{\mathrm{i}}^{\mathrm{N}}, \mathrm{N}_{\mathrm{i}}$ and $\mathrm{CO}_{\mathrm{i}-1}$ the peaks correspond to $\mathrm{N}_{\mathrm{i}}-\mathrm{CO}_{\mathrm{i}-1}$ and $\mathrm{N}_{\mathrm{i}-1}-\mathrm{CO}_{\mathrm{i}-2}$ correlations

separate dimensions. This allows to increase the CA-CB coupling evolution delay to $0.5 / \mathrm{J}_{\mathrm{CACB}}$ and therefore, to double (providing one ignores the relaxation) the sensitivity, which in the case of IDPs compensates for the extended pulse sequence. Although this sequence does not provide sequential connectivities, it allows to assign CA and $\mathrm{CB}$ chemical shifts and to identify a.a. residues by comparing the respective chemical shifts with typical values for each amino acid.

The 5D (H)NCO(NCA)CONH experiment is schematically depicted in Fig. 5a together with the scheme of coherence transfer pathway in protein backbone $5 \mathrm{~b}$. In this case the magnetization of amide proton's origin is transferred through amide nitrogen and carbonyl carbon nuclei back to nitrogen and to two different $\mathrm{CA}$ nuclei, then via the respective $\mathrm{CO}$ nuclei to the corresponding coupled $\mathrm{NH}$ pairs. In this case, again, ${ }^{13} \mathrm{CO}$ and ${ }^{15} \mathrm{~N}$ chemical shifts enable peak resolution in the 'fixed' dimensions $F_{3}$ and $F_{4}$, and establishing sequential connectivities from ${ }^{13} \mathrm{CO}$ and ${ }^{15} \mathrm{~N}$ in dimensions $F_{1}$ and $F_{2}$. 

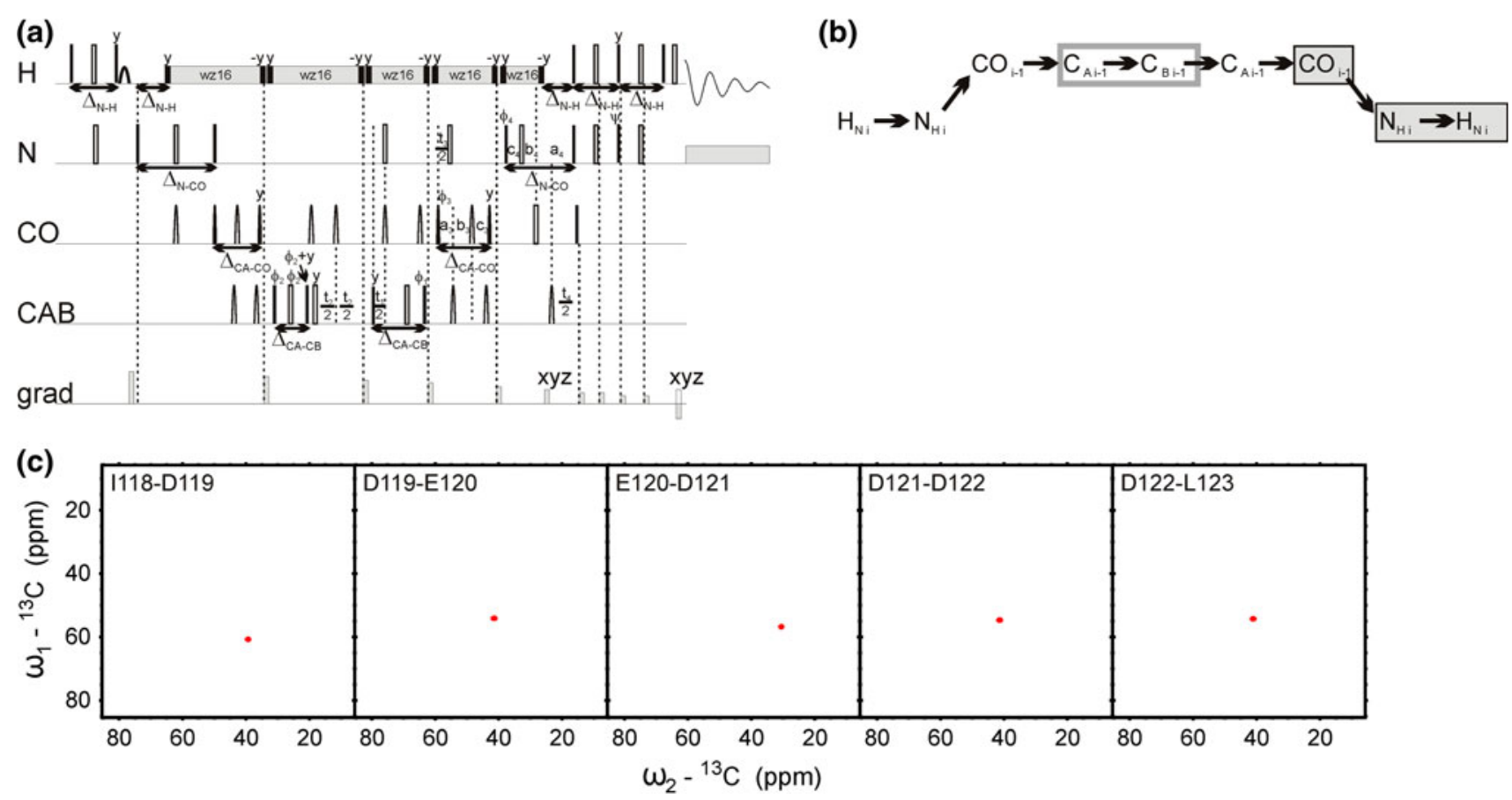

Fig. 4 5D HNCOCACB technique. (a) Pulse sequence, ${ }^{13} \mathrm{CO}$ and ${ }^{15} \mathrm{~N}$ evolution is in semi-constant-time mode: $\mathrm{a}_{\mathrm{i}}=\left(t_{\mathrm{i}}+\Delta\right) / 2$, $b_{\mathrm{i}}=t_{\mathrm{i}}\left(1-\Delta / t_{\mathrm{i}}^{\max }\right) / 2, c_{\mathrm{i}}=\Delta\left(1-t_{\mathrm{i}} / t_{\mathrm{i}}^{\max }\right) / 2$ (where $\Delta$ stands for listed below coherence transfer delays, $t_{\mathrm{i}}$ is the evolution time in $i$ th dimension and $t_{\mathrm{i}}^{\max }$ is maximal length of the evolution time delay). ${ }^{13} \mathrm{CA}$ chemical shift evolution is in constant-time mode. Delays were set as follows: $\Delta_{\mathrm{N}-\mathrm{H}}=5.4 \mathrm{~ms}, \Delta_{\mathrm{N}-\mathrm{CO}}=28.0 \mathrm{~ms}, \Delta_{\mathrm{CA}-\mathrm{CO}}=9.1 \mathrm{~ms}$, and $\Delta_{\mathrm{CACB}}=14.3 \mathrm{~ms}$. The four-step phase cycle was used: $\phi_{1}=\mathrm{x}$, $-\mathrm{x}, \phi_{2}=2 \mathrm{x}, 2(-\mathrm{x})$ and $\mathrm{Rec}=\phi_{1}+\phi_{2}$. The coherence selection gradients (marked by $x y z$ ) were applied at the magic angle. The phase

The $6 \mathrm{D}(\mathrm{H}) \mathrm{NCO}(\mathrm{N}) \mathrm{CACONH}$ pulse sequence is shown in Fig. 6. This sequence was obtained from the aforementioned 5D variant by introducing constant time evolution of CA frequencies, i.e. with no increase in overall sequence duration. The extra resolution gain resulting from the increased dimensionality may be crucial for IDPs' spectra that feature high chemical shift degeneracy. Such an example is given in Fig. 7, where the additional dimension enables to resolve peaks that still overlap in 5D spectra. In this case, however, application of SMFT procedure requires the knowledge of $\mathrm{CA}_{\mathrm{i}-1}$ chemical shifts. These shifts can be obtained using 5D HNCOCACB, 5D HabCabCONH (Kazimierczuk et al. 2010), or 4D HNCOCA (ZawadzkaKazimierczuk et al. 2010) experiments.

The experiments shown in Figs. 5 and 6 are conceptually similar to the (HACA)CON(CA)CONH experiment shown in Fig. 3, but the (HACA) fragment is replaced by $(\mathrm{H}) \mathrm{N}$. This modification enables application of band-selective excitation short-transient (BEST) approach that is aimed at the acceleration of acquisition (Schanda et al. 2006; Lescop et al. 2007), but does not allow to find the resonances of proline $\psi$ was inverted simultaneously with the last gradient pulse. (b) Coherence transfer in the peptide chain. $\mathrm{H}^{\mathrm{N}}, \mathrm{N}$, and $\mathrm{CO}$ frequencies (filled rectangles) are 'fixed' for Fourier transform. Frames for $\mathrm{CA}$ and $\mathrm{CB}$ indicate the dimensions of 2D cross-sections obtained by SMFT procedure. (c) $2 \mathrm{D}$ spectral planes for the $\delta$ subunit of $B$. subtilis RNA polymerase, which were obtained by SMFT procedure performed on the 5D randomly sampled signal (Poisson disk sampling) with 'fixed' frequencies obtained from 3D HNCO peak list. Each cross-section contains one cross-peak: for 'fixed' $\mathrm{H}_{\mathrm{i}}^{\mathrm{N}}, \mathrm{N}_{\mathrm{i}}$ and $\mathrm{CO}_{\mathrm{i}-1}$ the peak corresponds to $\mathrm{CA}_{\mathrm{i}-1}-\mathrm{CB}_{\mathrm{i}-1}$ correlation

residues. Notably, the (H)NCO(NCA)CONH sequence has a sensitivity advantage over the (HACA)CON(CA)CONH sequence as the $\mathrm{CA} \rightarrow \mathrm{CO}$ coherence transfer in the latter is attenuated due to the presence of a concurrent ${ }^{1} \mathrm{~J}_{\mathrm{CACB}}$ coupling. The respective amplitude transfer functions at this point (i.e. before the first $\mathrm{CO}$ evolution period) are shown in (1) and (2) below:

$$
\begin{aligned}
\mathrm{I}(\mathrm{HN})= & \sin ^{2}\left(\pi \mathrm{J}_{\mathrm{NH}} \Delta_{\mathrm{NH}}\right) \sin \left(\pi \mathrm{J}_{\mathrm{NCO}} \Delta_{\mathrm{NCO}}\right) \exp \left(-\Delta_{\mathrm{NH}} / \mathrm{T}_{2 \mathrm{HN}}\right. \\
& \left.-\Delta_{\mathrm{NCO}} / \mathrm{T}_{2 \mathrm{~N}}\right)
\end{aligned}
$$

$$
\begin{aligned}
& \mathrm{I}(\mathrm{HACA})=\sin \left(\pi \mathrm{J}_{\mathrm{HC}} \Delta_{\mathrm{HC}}\right) \sin \left(\pi \mathrm{J}_{\mathrm{HC}} \Delta_{\mathrm{HC}}^{\prime}\right) \\
& \cos ^{\mathrm{n}-1}\left(\pi \mathrm{J}_{\mathrm{HC}} \Delta_{\mathrm{HC}}^{\prime}\right) \sin \left(\pi \mathrm{J}_{\mathrm{CACO}} \Delta_{\mathrm{CACO}}\right) \cos \left(\pi \mathrm{J}_{\mathrm{CACB}} \Delta_{\mathrm{CACO}}\right) \\
& \exp \left(-\Delta_{\mathrm{HC}} / \mathrm{T}_{2 \mathrm{HA}}-\Delta_{\mathrm{CACO}} / \mathrm{T}_{2 \mathrm{CA}}\right)
\end{aligned}
$$

where $\mathrm{n}$ is the number of HA protons (for Gly: $\mathrm{n}=2$ ).

We have set $\Delta_{\mathrm{CACO}}=6.8 \mathrm{~ms}$ to compromise between J-couplings and relaxation. The same choice was made by Mäntylahti et al. (2011) for other HA-excited experiments 

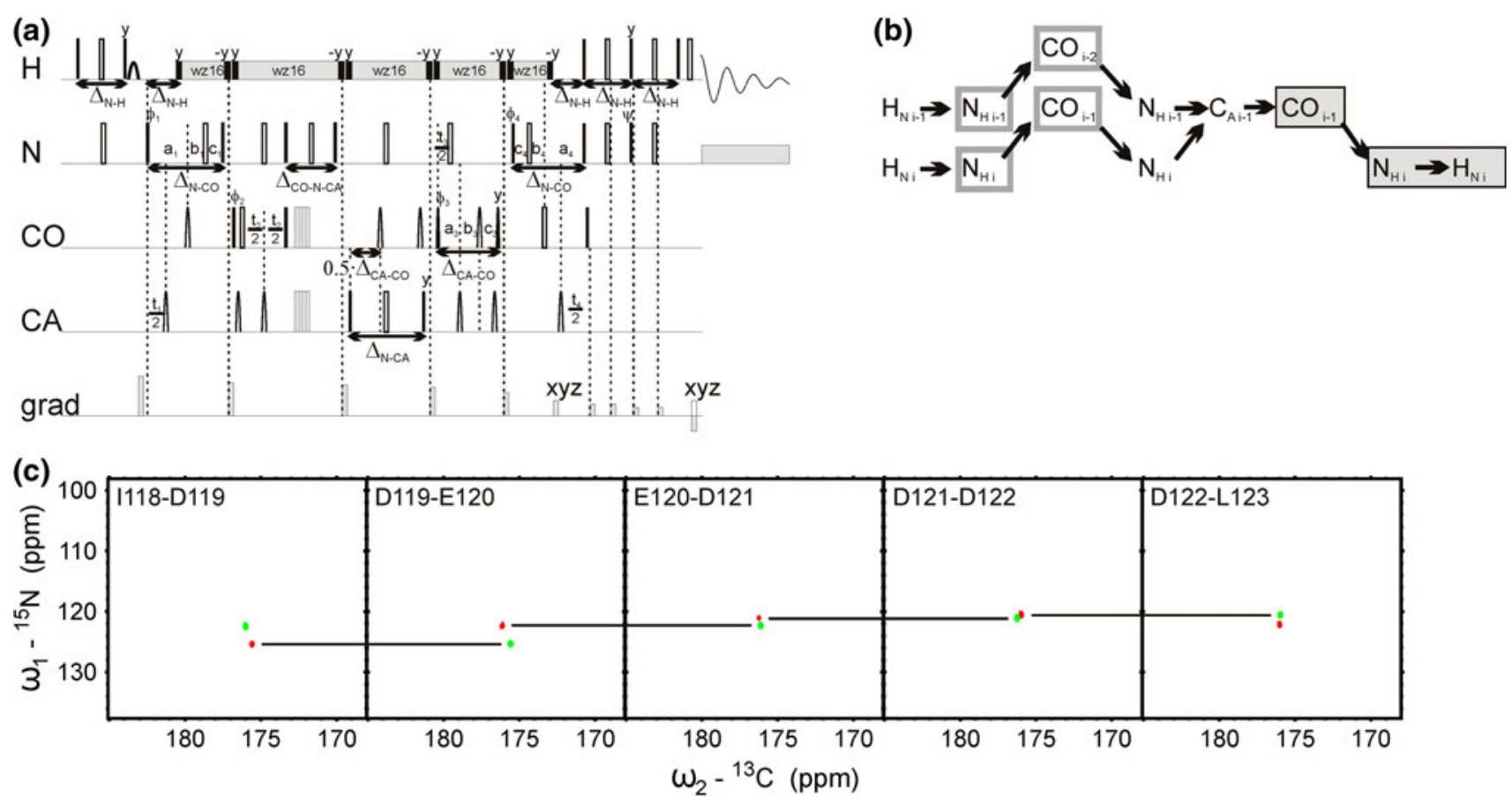

Fig. 5 D (H)NCO(NCA)CONH technique. (a) Pulse sequence, ${ }^{15} \mathrm{~N}$ (in $t_{1}$ and $t_{4}$ ) and ${ }^{13} \mathrm{CO}$ (in $t_{3}$ ) evolution is in semi-constant-time mode: $\quad \mathrm{a}_{\mathrm{i}}=\left(t_{\mathrm{i}}+\Delta\right) / 2, \quad b_{\mathrm{i}}=t_{\mathrm{i}}\left(1-\Delta / t_{\mathrm{i}}^{\max }\right) / 2, \quad c_{\mathrm{i}}=\Delta\left(1-t_{\mathrm{i}} / t_{\mathrm{i}}^{\max }\right) / 2$ (where $\Delta$ stands for listed below coherence transfer delays, $t_{\mathrm{i}}$ is the evolution time in $i$ th dimension and $t_{\mathrm{i}}^{\max }$ is maximal length of the evolution time delay). Delays were set as follows: $\Delta_{\mathrm{N}-\mathrm{H}}=5.4 \mathrm{~ms}$, $\Delta_{\mathrm{N}-\mathrm{CO}}=28.0 \mathrm{~ms}, \Delta_{\mathrm{CO}-\mathrm{N}-\mathrm{CA}}=28.0 \mathrm{~ms}, \Delta_{\mathrm{N}-\mathrm{CA}}=28.6 \mathrm{~ms}$, and $\Delta_{\mathrm{CA}-}$ $\mathrm{co}=9.1 \mathrm{~ms}$. The four-step phase cycle was used: $\phi_{1}=\mathrm{x},-\mathrm{x}$, $\phi_{2}=2 \mathrm{x}, 2(-\mathrm{x})$ and $\mathrm{Rec}=\phi_{1}+\phi_{2}$. Simultaneous inversion of CA and $\mathrm{CO}$ spins was achieved using 6-element composite pulse (Shaka 1985). The coherence selection gradients (marked by xyz) were

and is usually employed in HSQC type $\mathrm{HN}(\mathrm{CA}) \mathrm{CO}$ experiments (for references see Sattler et al. 1999). Assuming $\mathrm{T}_{2 \mathrm{HN}}=50 \mathrm{~ms}, \mathrm{~T}_{2 \mathrm{~N}}=50 \mathrm{~ms}, \mathrm{~T}_{2 \mathrm{HA}}, \mathrm{T}_{2 \mathrm{CA}}=20 \mathrm{~ms}$, $\mathrm{n}=1$, and delay times as given in figure captions, we obtain 0.50 and 0.36 for $\mathrm{I}(\mathrm{HN})$ and I(HACA), respectively. Setting $\Delta_{\mathrm{CACO}}$ at $28.5 \mathrm{~ms}$, which is close to $1 / \mathrm{J}_{\mathrm{CACB}}$, with evolution of $\mathrm{J}_{\mathrm{CACO}}$ extended to $9.1 \mathrm{~ms}$, further reduces I(HACA) to 0.18 . Using the relaxation times $\mathrm{T}_{2 \mathrm{HN}}=80 \mathrm{~ms}, \mathrm{~T}_{2 \mathrm{~N}}=$ $100 \mathrm{~ms}, \mathrm{~T}_{2 \mathrm{HA}}=40 \mathrm{~ms}$ and $\mathrm{T}_{2 \mathrm{CA}}=50 \mathrm{~ms}$, which seem likely for IDPs (based on our experience), and $\Delta_{\mathrm{CACO}}=$ $6.8 \mathrm{~ms}$, one obtains $\mathrm{I}(\mathrm{HN})=0.68$ and $\mathrm{I}(\mathrm{HACA})=0.49$, whereas for $\Delta_{\mathrm{CACO}}$ of $28.5 \mathrm{~ms} \mathrm{I}(\mathrm{HACA})=0.47$. Therefore, the latter option seems impractical, especially that the relaxation rates and coupling constants may not be uniform in the entire molecule.

Despite long duration of the proposed pulse sequences and high sparsity of the sampling schedules employed we have found all expected peaks for the disordered fragment of $B$. subtilis RNA polymerase $\delta$ subunit. We have not found any false peaks, i.e. all resonances found were unambiguously assigned in a sequential manner. applied at the magic angle. The phase $\psi$ was inverted simultaneously with the last gradient pulse. (b) Coherence transfer in the peptide chain. $\mathrm{H}^{\mathrm{N}}, \mathrm{N}$, and $\mathrm{CO}$ frequencies (filled rectangles) are 'fixed' for Fourier transform. Frames for $\mathrm{N}$ and $\mathrm{CO}$ indicate the dimensions of 2D cross-sections obtained by SMFT procedure. (c) 2D spectral planes for the $\delta$ subunit of $B$. subtilis RNA polymerase, which were obtained by SMFT procedure performed on the $5 \mathrm{D}$ randomly sampled signal (Poisson disk sampling) with 'fixed' frequencies obtained from 3D HNCO peak list. Each cross-section contains two cross-peaks: for 'fixed' $\mathrm{H}_{\mathrm{i}}^{\mathrm{N}}, \mathrm{N}_{\mathrm{i}}$ and $\mathrm{CO}_{\mathrm{i}-1}$ the peaks correspond to $\mathrm{N}_{\mathrm{i}}-\mathrm{CO}_{\mathrm{i}-1}$ and $\mathrm{N}_{\mathrm{i}-1}-\mathrm{CO}_{\mathrm{i}-2}$ correlations

In Fig. 8, non-specificity of aliphatic ${ }^{1} \mathrm{H}$ and ${ }^{13} \mathrm{C}$ chemical shifts is demonstrated using E168-E171 correlations for $\delta$ subunit of RNA polymerase from B. subtilis. It is shown that in the repeated glutamic acid fragment the aliphatic chemical shifts do not differ sufficiently for the sequential assignment, while amide nitrogen and carbonyl carbon chemical shifts enable unambiguous assignment.

\section{Conclusions}

Random sampling and SMFT processing allow developing novel NMR experiments of high dimensionality and high resolution that would not be feasible using conventional sampling. The new experiments enable simple and unambiguous backbone assignment of IDPs. Importantly, not all of the presented techniques must be used to obtain complete sequential assignment. One can combine various experiments (also from among those published before) to construct an optimal set for a given protein. The use of the 

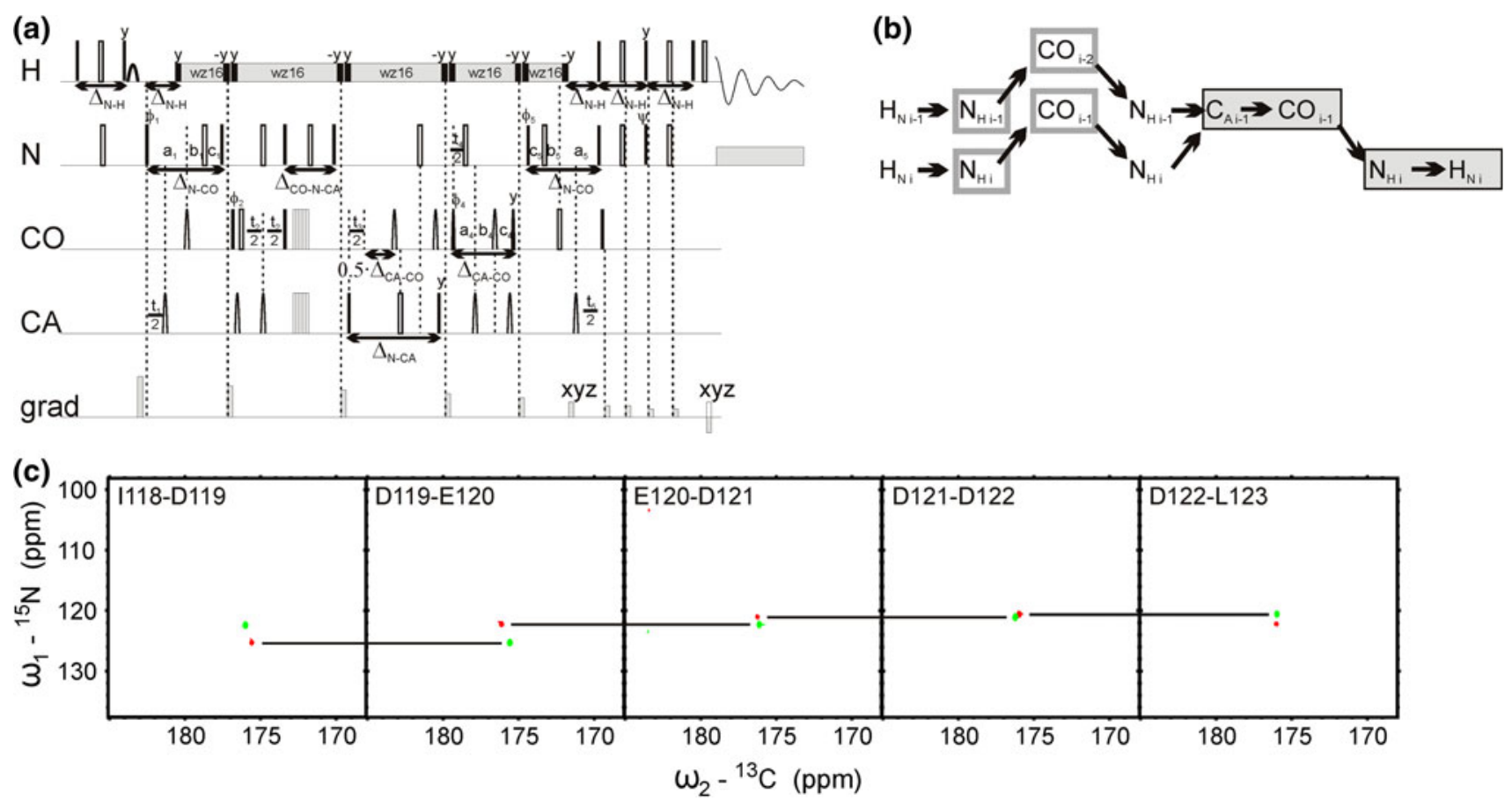

Fig. 6 6D (H)NCO $(\mathrm{N}) \mathrm{CACONH}$ technique. (a) Pulse sequence, ${ }^{15} \mathrm{~N}$ (in $t_{1}$ and $t_{5}$ ) and ${ }^{13} \mathrm{CO}$ (in $t_{4}$ ) evolution is in semi-constant-time mode: $\quad a_{\mathrm{i}}=\left(t_{\mathrm{i}}+\Delta\right) / 2, \quad b_{\mathrm{i}}=t_{\mathrm{i}}\left(1-\Delta / t_{\mathrm{i}}^{\max }\right) / 2, \quad c_{\mathrm{i}}=\Delta\left(1-t_{\mathrm{i}} / t_{\mathrm{i}}^{\max }\right) / 2$ (where $\Delta$ stands for listed below coherence transfer delays, $t_{\mathrm{i}}$ is the evolution time in $i$ th dimension and $t_{\mathrm{i}}^{\max }$ is maximal length of the evolution time delay). CA evolution (in $t_{3}$ ) is in constant-time mode. Delays were set as follows: $\Delta_{\mathrm{N}-\mathrm{H}}=5.4 \mathrm{~ms}, \Delta_{\mathrm{N}-\mathrm{CO}}=28.0 \mathrm{~ms}$, $\Delta_{\mathrm{CO}-\mathrm{N}-\mathrm{CA}}=28.0 \mathrm{~ms}, \Delta_{\mathrm{N}-\mathrm{CA}}=28.6 \mathrm{~ms}$, and $\Delta_{\mathrm{CA}-\mathrm{CO}}=9.1 \mathrm{~ms}$. The four-step phase cycle was used: $\phi_{1}=\mathrm{x},-\mathrm{x}, \phi_{2}=2 \mathrm{x}, 2(-\mathrm{x})$ and $\operatorname{Rec}=\phi_{1}+\phi_{2}$. Simultaneous inversion of CA and CO spins was achieved using 6-element composite pulse (Shaka 1985). The coherence selection gradients (marked by $x y z$ ) were applied at the magic angle. The phase $\psi$ was inverted simultaneously with the last gradient pulse. (b) Coherence transfer in the peptide chain. $\mathrm{H}^{\mathrm{N}}, \mathrm{N}, \mathrm{CO}$ and $\mathrm{CA}$ frequencies (filled rectangles) are 'fixed' for Fourier transform. Frames for $\mathrm{N}$ and $\mathrm{CO}$ indicate the dimensions of $2 \mathrm{D}$ cross-sections obtained by SMFT procedure. (c) 2D spectral planes for the $\delta$ subunit of $B$. subtilis RNA polymerase, which were obtained by SMFT procedure performed on the $6 \mathrm{D}$ randomly sampled signal (Poisson disk sampling) with 'fixed' frequencies obtained from 4D HNCOCA peak list. Each plane contains two cross-peaks: for 'fixed' $\mathrm{H}_{\mathrm{i}}^{\mathrm{N}}, \mathrm{N}_{\mathrm{i}}, \mathrm{CO}_{\mathrm{i}-1}$ and $\mathrm{CA}_{\mathrm{i}-1}$ the peaks correspond to $\mathrm{N}_{\mathrm{i}}-\mathrm{CO}_{\mathrm{i}-1}$ and $\mathrm{N}_{\mathrm{i}-1}-\mathrm{CO}_{\mathrm{i}-2}$ correlations (a)

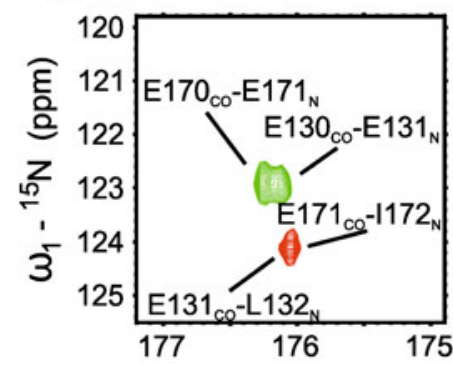

(b)

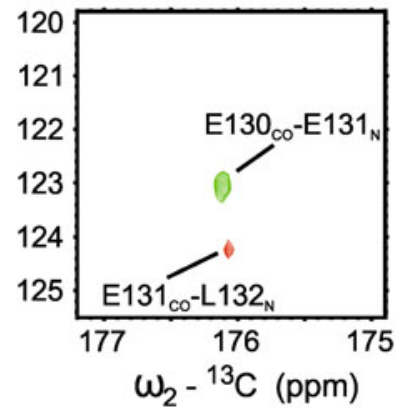

(c)

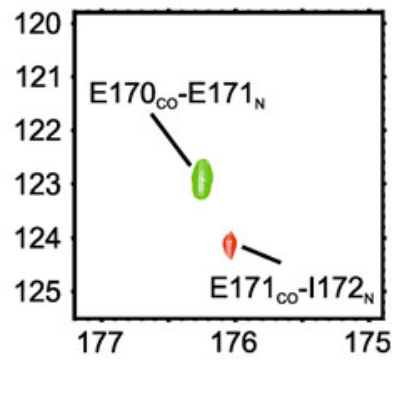

Fig. 7 Comparison of 2D N-CO cross-sections from 5D (H)NCO(N$\mathrm{CA}) \mathrm{CONH}(\mathbf{a})$ and $6 \mathrm{D}(\mathrm{H}) \mathrm{NCO}(\mathrm{N}) \mathrm{CACONH}(\mathbf{b}, \mathbf{c})$ experiments. In 5D experiment (a) the two pairs of correlation peaks overlap (E130/ E131 with E170/E171, and E131/L132 with E171/I172) due to

techniques we present in this paper provides sequential connectivities via ${ }^{13} \mathrm{CO}$ and ${ }^{15} \mathrm{~N}$ chemical shifts and enables more straightforward sequential assignment than the 5D experiments published previously. Moreover, the similarity of chemical shifts for all 'fixed' dimensions: $\mathrm{H}_{\mathrm{L} 132}^{\mathrm{N}}$ and $\mathrm{H}_{\mathrm{I} 172}^{\mathrm{N}}, \mathrm{N}_{\mathrm{L} 132}$ and $\mathrm{N}_{\mathrm{I} 172}, \mathrm{CO}_{\mathrm{E} 131}$ and $\mathrm{CO}_{\mathrm{E} 171}$. The additional $\mathrm{CA}$ dimension in $6 \mathrm{D}$ experiment $(\mathbf{b}, \mathbf{c})$ enabled to differentiate and assign all peaks

separation of individual spin systems on 2D cross-sections could be very useful for a possible automatic assignment algorithm, which would allow fast and simple resonance assignment, also for large IDPs. 
Fig. $8 F_{1}-F_{2} 2 \mathrm{D}$ cross-sections of $\mathrm{HACA}(\mathrm{N}) \mathrm{CONH}(\mathbf{a})$, HNCOCACB (b), and (H)NCO(NCA)CONH (c) 5D experiments, acquired for the $\delta$ subunit of $B$. subtilis RNA polymerase, show E168E171correlations. The two intraand inter-residual HA-CA correlation peaks are not resolved in (a); CA-CB correlation peaks in (b) have identical coordinates, however, the resolved pairs of $\mathrm{N}-\mathrm{CO}$ peaks shown in (c) enable unambiguous sequential assignment
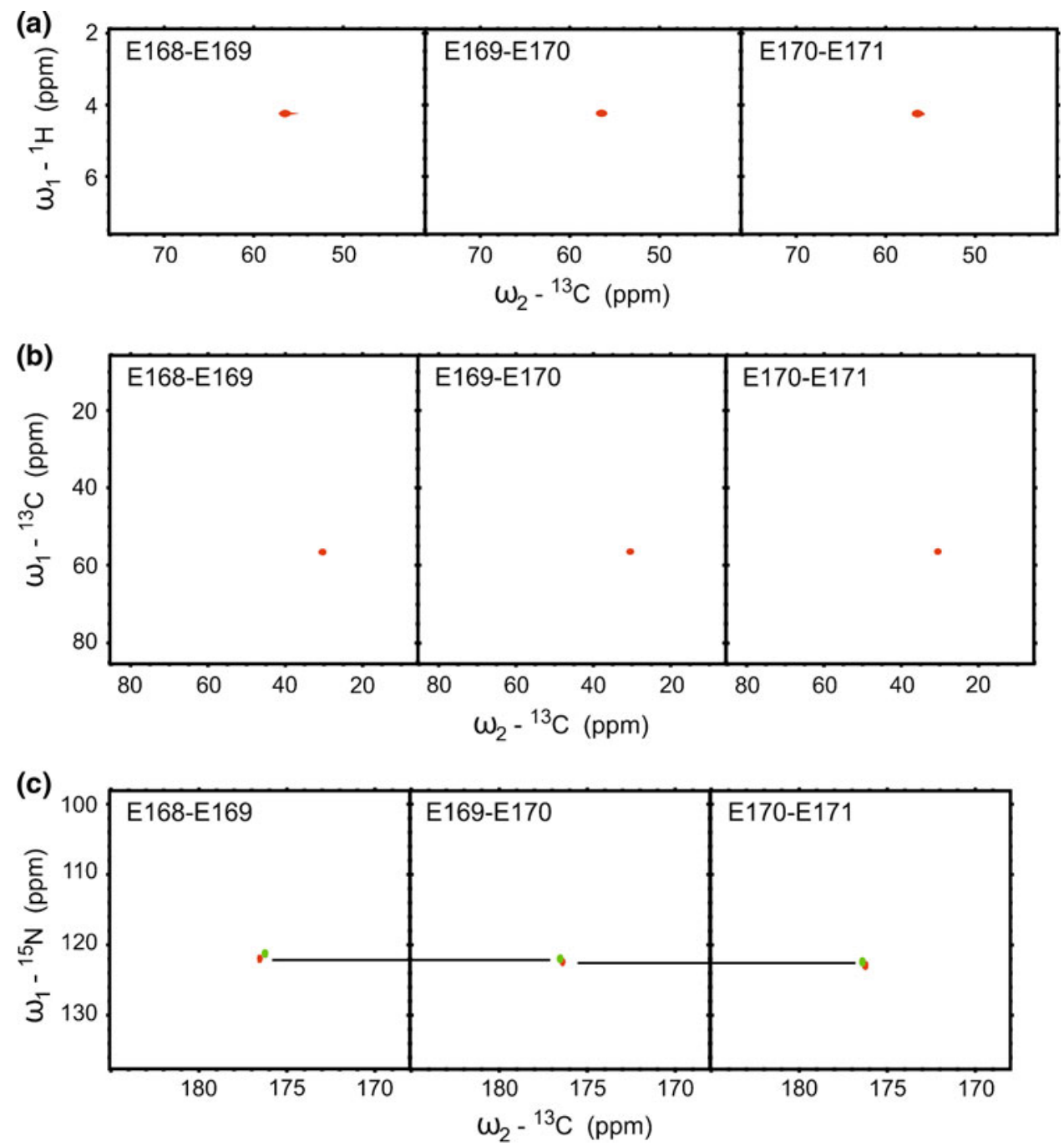

Acknowledgments This work has been supported by the Bio-NMR project under the 7th framework programme of the EC grant agreement 261863 for conducting the research. The authors thank Dr. Stanisław Chrapusta of the Mossakowski Medical Research Center, Polish Academy of Sciences, for his assistance in language correction. A.Z.-K. thanks the Foundation for Polish Science for supporting her with the MPD Programme that was co-financed by the EU European Regional Development Fund. H.S. and L.K. acknowledge support by Grant No. 204/09/0583 from the Czech Science Foundation and Institutional Research Concept No. AV0Z50200510.

Open Access This article is distributed under the terms of the Creative Commons Attribution License which permits any use, distribution, and reproduction in any medium, provided the original author(s) and the source are credited.

\section{References}

Bermel W, Bertini I, Felli IC, Piccioli M, Pierattelli R (2006) ${ }^{13} \mathrm{C}$ detected protonless NMR spectroscopy of proteins in solution. Prog Nucl Magn Reson Spectrosc 48:25-45
Bermel W, Bertini I, Csizmok V, Felli IC, Pierattelli R, Tompa P (2009) H-start for exclusively heteronuclear NMR spectroscopy: the case of intrinsically disordered protein. J Magn Reson 198:275-281

Coggins BE, Venters RA, Zhou P (2010) Radial sampling for fast NMR: concepts and practices over three decades. Prog Nucl Magn Reson Spectrosc 57:381-419

Dyson HJ, Wright PE (2001) Nuclear magnetic resonance methods for elucidation of structure and dynamics in disordered states. Methods Enzymol 339:258-270

Dyson HJ, Wright PE (2005) Intrinsically unstructured proteins and their functions. Natl Rev Mol Cell Biol 6:197-208

Felli IC, Brutscher B (2009) Recent advancements in solution NMR: fast methods and heteronuclear direct detection. ChemPhysChem 10:1356-1368

Goddard TD, Kneller DG (2002) SPARKY 3. University of California, San Francisco. http://www.cgl.ucsf.edu/home/sparky

Grzesiek S, Bax A (1992a) Correlating backbone amide and side chain resonances in larger proteins by multiple relayed triple resonance NMR. J Am Chem Soc 114:6291-6293

Grzesiek S, Bax A (1992b) An efficient experiment for sequential backbone assignment of medium sized isotopically enriched proteins. J Magn Reson 99:201-207 
Grzesiek S, Bax A (1993) Amino acid type determination in the sequential assignment procedure of uniformly $13 \mathrm{C} / 15 \mathrm{~N}$ enriched proteins. J Biomol NMR 3:185-204

Kazimierczuk K, Zawadzka A, Koźmiński W (2008) Optimization of random time domain sampling in multidimensional NMR. J Magn Reson 192:123-130

Kazimierczuk K, Zawadzka A, Koźmiński W (2009) Narrow peaks and high dimensionalities: exploiting the advantages of random sampling. J Magn Reson 197:219-228

Kazimierczuk K, Stanek J, Zawadzka-Kazimierczuk A, Koźmiński W (2010a) Random sampling in multidimensional NMR spectroscopy. Prog Nucl Magn Reson Spectrosc 57:420-434

Kazimierczuk K, Zawadzka-Kazimierczuk A, Koźmiński W (2010b) Non-uniform frequency domain for optimal exploitation of nonuniform sampling. J Magn Reson 205:286-292

Lescop E, Schanda P, Brutscher B (2007) A set of BEST tripleresonance experiments for time-optimized protein resonance assignment. J Magn Reson 187:163-169

Mäntylahti S, Hellman M, Permi P (2011) Extension of the HA-detection based approach: (HCA)CON(CA)H and (HCA) $\mathrm{NCO}(\mathrm{CA}) \mathrm{H}$ experiments for the main-chain assignment of intrinsically disordered proteins. J Biomol NMR 49:99-109

Motáčková V, Nováček J, Zawadzka-Kazimierczuk A, Kazimierczuk K, Žídek L, Šanderová H, Krásný L, Koźmiński W, Sklenáŕ V (2010) Strategy for complete NMR assignment of disordered proteins with highly repetitive sequences based on resolutionenhanced 5D experiments. J Biomol NMR 48:169-177

Narayanan RL, Durr UHN, Bibow S, Biernat J, Mandelkow E, Zweckstetter M (2010) Automatic assignment of the intrinsically disordered protein tau with 441-residues. J Am Chem Soc 132(34):11906-11907

Nováček J, Zawadzka-Kazimierczuk A, Papoušková V, Žídek L, Šanderová H, Krásný L, Koźmiński W, Sklenáŕ V (2011) 5D ${ }^{13} \mathrm{C}$ detected experiments for backbone assignment of unstructured proteins with a very low signal dispersion. J Biomol NMR 50:1-11

Sattler M, Schleucher J, Griesinger C (1999) Heteronuclear multidimensional NMR experiments for the structure determination of proteins in solution employing pulsed field gradients. Prog Nucl Magn Reson Spectrosc 34:93-158

Schanda P, Van Melckebeke H, Brutscher B (2006) Speeding up three-dimensional protein NMR experiments to a few minutes. J Am Chem Soc 128:9042-9043

Shaka AJ (1985) Composite pulses for ultra-broadband spin inversion. Chem Phys Lett 120:201-205

Tompa P (2010) Structure and function of intrinsically disordered proteins. CRC Press, Boca Raton

Tompa P, Dosztanyi Z, Simon I (2006) Prevalent structural disorder in E. coli and S. cerevisiae proteomes. J Proteome Res 5:1996-2000

Ward JJ, Sodhi JS, McGuffin LJ, Buxton BF, Jones DT (2004) Prediction and functional analysis of native disorder in proteins from the three kingdoms of life. J Mol Biol 337:635-645

Wen J, Wu J, Zhou P (2011) Sparsely sampled high-resolution 4-D experiments for efficient backbone resonance assignment of disordered proteins. J Magn Reson 209:94-100

Wittekind M, Müller I (1993) HNCACB, a high-sensitivity 3D NMR experiment to correlate amide-proton and nitrogen resonances with the alpha- and beta-carbon resonances in proteins. J Magn Reson B 101:201-205

Zawadzka-Kazimierczuk A, Kazimierczuk K, Koźmiński W (2010) A set of 4D NMR experiments of enhanced resolution for easy resonance assignment in proteins. J Magn Reson 202:109-116 